\title{
Mecanismo de los AINES y antiinflamatorios derivados para el control del dolor y la inflamación. Uso de antiinflamatorios en odontología.
}

\author{
Mechanism of NSAIDs and derived drugs for pain and inflammation \\ control. Use of anti-inflammatories in odontology.
}

\author{
Alberth Francisco Keb Canul*
}

\section{RESUMEN}

Las urgencias odontológicas son, quizá, las razones principales de atención en el consultorio, muchas veces el significado de dolor se encuentra acompañado por inflamación; el uso de antiinflamatorios no esteroideos (AINES) es común en el ejercicio de la odontología por la excelente respuesta analgésica y antiinflamatoria que tiene, por lo que es importante conocer la fisiopatología de la inflamación y el dolor y cómo actúan los AINES, ya que algunos de estos fármacos tienen respuestas adversas y sitios de acción importantes. Los factores de riesgo por inflamación y dolor nos obligan a conocer la variedad de fármacos que no entran en la clasificación de AINES y que tenemos a disposición, hay más opciones para la elección ante la presencia de inflamación por un factor en particular, cada uno de éstos tienen indicaciones y contraindicaciones que conoceremos, lo cual nos ampliará el conocimiento para dar una prescripción ante la presencia de eventos inflamatorios. Se realizó un estudio detallado de artículos bibliográficos de cada tema, los fármacos más usados en odontología son los AINES, hay poco uso y conocimiento de antiinflamatorios que podemos usar en urgencias, el porcentaje de uso de los AINES derivados del ácido propiónico es alto por la excelente respuesta en pacientes y otras veces por el desconocimiento de más opciones.

Palabras clave: AINES, inflamación, dolor, ciclooxigenasa, narcótico, desinflamatorio.

\section{ABSTRACT}

Dental emergencies are perhaps the main reasons for care in the office, many times the meaning of pain is accompanied by inflammation, the use of non-steroidal anti-inflammatory drugs is common in the practice of dentistry due to the excellent analgesic and anti-inflammatory response it has, important is knowing the pathophysiology of inflammation and pain, how NSAIDs act, some of these drugs have adverse responses and important sites of action, risk factors for inflammation and pain require us to know the variety of drugs that do not enter the classification of NSAIDs and we have at our disposal, there are more options for choosing in the presence of inflammation due to a particular factor, each of these have indications and contraindications that we will know, it expands our knowledge to give a prescription in the presence of inflammatory events. A detailed study of bibliographic articles on each topic was carried out, the drugs most used in dentistry are NSAIDs, there is little use and knowledge of anti-inflammatories that we can use in the emergency room, the percentage of use of NSAIDs derived from propionic acid is high, due to the excellent response in patients and others due to lack of knowledge of more options.

Keywords: NSAIDs, inflammation, pain, cyclooxygenase, narcotic, anti-inflammatory.

* Licenciado en Odontología. Hospital Centro Médico Pensiones. Mérida, Yucatán, México.

Recibido: 12 de julio de 2021. Aceptado: 11 de enero de 2022.

Citar como: Keb CAF. Mecanismo de los AINES y antiinflamatorios derivados para el control del dolor y la inflamación. Uso de antiinflamatorios en odontología. Rev ADM. 2022; 79 (1): 38-47. https://dx.doi.org/10.35366/103817 


\section{INTRODUCCIÓN}

$\mathrm{U}$ no de los problemas más comunes que se encuentran durante la práctica odontológica son las agresiones a tejidos bucofaciales y con ello sabemos que una de las principales causas son las infecciones bacterianas; al presentarse la infección, en un periodo de tiempo determinado, la inflamación se presenta como respuesta de autodefensa del sistema inmune. En la práctica diaria, el estomatólogo se enfrenta a diversas causas posibles de una inflamación, como pueden ser físicas, químicas o biológicas. En la actualidad, los analgésicos de primera elección o los que más se usan en el mundo son los antiinflamatorios no esteroideos (AINES) por ser de los más completos en propiedades al momento de la prescripción; sin embargo, también es importante conocer cuál es su sitio de acción y con ello las contraindicaciones que puede traer ante la medicación de un paciente..$^{1,2}$

Cabe destacar que el mecanismo de acción de los AINES es la inhibición de la ciclooxigenasa (COX) y en dicha enzima se encuentran sustancias involucradas en la inflamación, como las prostaglandinas, al haber presencia de PG12 también habrá inflamación, con ello podemos corroborar su acción como antiinflamatoria y diferenciar de un desinflamatorio. Para poder saber las contraindicaciones, es necesario comprender que las PG12 al cumplir una función de respuesta por algún mecanismo inflamatorio también cumplen con tareas de homeostasis en el sistema, los factores inflamatorios pueden ser físicos, químicos o biológicos, por lo que es importante conocer los diversos fármacos de los que podemos hacer uso a la hora de una urgencia odontológica y que la variedad de medicamentos que tenemos tienen sitio de acción tanto central como periférica. Por ello, a lo largo del texto iremos conociendo la acción de dichos fármacos y cómo realizar una buena elección para, de esta manera, lograr el objetivo deseado y dar una atención correcta al paciente. ${ }^{1-3}$
Objetivos. Conocer los mecanismos de acción de la inflamación y el dolor, todos y cada uno de los mediadores involucrados y saber el trabajo a nivel sistémico de los fármacos, conocer la gran variedad de fármacos antiinflamatorios que tenemos al alcance del ejercicio de la atención odontológica y cada una de sus indicaciones dependiendo de la situación que se presente, además de sus interacciones.

\section{MATERIAL Y MÉTODOS}

El diseño del estudio fue mediante revisiones de diferentes artículos bibliográficos con un análisis detallado de cada sección mencionada en este trabajo, como lo son las principales causas de inflamación y dolor, la respuesta fisiopatológica de cada una de ellas comprendida a nivel sistémico y el uso de los principales antiinflamatorios en la práctica odontológica; además, se realizó un análisis detallado de otros antiinflamatorios no muy comunes en el campo odontológico, todo esto con la finalidad de ampliar la carpeta de fármacos que tenemos y sus principales usos. El análisis estadístico se realizó mediante las investigaciones bibliográficas.

\section{Fisiopatología de la inflamación}

Para entender el mecanismo de los AINES es importante conocer cómo se da inicio a la inflamación, y ésta tiene lugar por diferentes respuestas a estímulos agresivos hacia una zona, en estos estímulos podemos encontrar los físicos, químicos y biológicos (Tabla 1). El sistema tiene una reacción de autodefensa ante dicha agresión y busca adaptar al cuerpo a la presencia de células que no son cotidianas (Figura 1), por ello, al existir una agresión la enzima ciclooxigenasa (COX) manda de inmediato al ácido araquidónico al sitio de acción, el cual se convierte en prostaglandinas, prostaciclina, tromboxanos y leucotrienos, y las transforma en histamina, serotonina, bradicinina, eicosanoides, éstos

Tabla 1: Factores que predisponen la inflamación.

Agentes

Físicos

Biológicos

Químicos
Ejemplos

Traumáticas por accidentes, cirugías en cavidad oral

Infecciones por bacterias, virus, hongos, insuficiente aporte vitamínico, esclerodermia, dermatomiositis Agentes irritantes tales como toxinas 
Tabla 2: Sitios de acción hemostática de la ciclooxigenasa.

\begin{tabular}{ccc} 
COX-1 & COX-2 & COX-2 \\
Constitutiva & Constitutiva & Inducida (provocada) \\
\hline $\begin{array}{c}\text { Función gástrica (formación de moco intestinal) } \\
\text { Vasodilatador } \\
\text { Hepático } \\
\text { Glomerular }\end{array}$ & $\begin{array}{c}\text { Nivel cardiológico } \\
\text { Vasos sanguíneos }\end{array}$ & Se presenta en traumas y es la que se busca inhibir por inflamación \\
& \\
\hline
\end{tabular}

\section{Tabla 3: Funciones de los antiinflamatorios no esteroideos.}

Función

Analgésico

Antipirético

Antiinflamatorio

Antiagregante plaquetario

Antitrombótico
Mecanismo

Inhibidor de síntesis de prostaglandina no hay agregación de bradiquininas

estimulantes de vasodilatación e hipersensibilidad de terminaciones nerviosas

Inhibidor de la ciclooxigenasa y de la síntesis de tromboxano A2 como consecuencia la no agregación plaquetaria

Inhibidor de la ciclooxigenasa mediante la oxidación de ácido araquidónico

Inhibidor de la ciclooxigenasa mediante la inhibición de la síntesis de tromboxano A2

Inhibidor de la ciclooxigenasa y de la inhibición de la síntesis de tromboxano A2 son los principales mediadores del proceso inflamatorio e inician su acción, por lo que hay un aumento del diámetro vascular, esto es inducido por el endotelio al mandar inmediatamente dichas células de protección y con ello la permeabilidad capilar por el flujo sanguíneo aumentado para dicha protección y, por ende, la causa del edema (tumor). 2,4-7

\section{Fisiopatología del dolor}

El colágeno, las endotoxinas, el cartílago y el factor de Hageman activan la proteína calicreína que a su vez activa las cininas, que son moléculas que se presentan al existir inflamación, y dicha activación produce bradiquinina (que es inducido mediante la secreción de prostaciclinas presentes en la COX) y calicreína (que son moléculas que aumentan la permeabilidad vascular), lo cual induce la vasodilatación y el dolor. $4,7,8$

\section{Mecanismo de la ciclooxigenasa (COX)}

Entendido el mecanismo de la inflamación, ahora podemos conocer las múltiples tareas que la enzima COX tiene en el sistema, además de tener participación en la inflamación y el dolor es importante mencionar que su acción homeostática es fundamental para algunas partes del cuerpo humano al activar ciertos mediadores que dan el equilibrio balanceado para mantener una homeostasis. Por otra parte, se sabe que la COX se divide en tres partes: COX-1 constitutiva, COX-2 constitutiva y COX-2 inducida (Tabla 2). 2,5,9,10

Para comprenderlo recordemos que la ciclooxigenasa es participe de la homeostasis del cuerpo, por lo que tiene acción protectora en diferentes partes de la anatomía humana, de manera que la COX-1 y COX-2 son constitutivas, ya que están presentes en el sistema secretando células protectoras a una zona en particular, por ende la COX-2 inducida es la que hace su presencia ante una acción de agresión como las mencionadas (físicas, químicas y biológicas) y ésta es la que se busca bloquear ante la presencia de dolor e inflamación. 2,5,9,10

En la búsqueda del bloqueo de dichos mediadores inflamatorios y de dolor presentes en la COX-2 inducida es importante conocer los sitios de acción de la COX-1 y COX-2 constitutivas para que en el momento 
de prescribir AINES sepamos qué otras zonas estaremos bloqueando, por lo cual estaríamos también inhibiendo los agentes protectores inducidos por la ciclooxigenasa. $2,5,9,10$

\section{Mecanismo de los AINES en la COX}

Después de saber la fisiopatología de la inflamación podemos abordar el mecanismo de acción de los AINES, la tarea principal es inhibir la enzima ciclooxigenasa mediante la oxidación del ácido araquidónico impidiendo así que se convierta en prostaglandinas y los mediadores de la inflamación no se presenten.1,4 Las funciones que cumplen son analgésico, antipirético, antiinflamatorio, antiagregante plaquetario y antitrombótico (Tabla 3). 1,10

La inhibición de dichas enzimas COX al agregar prostaglandinas y tromboxano también repercute en diferentes partes de la anatomía humana, recordemos que cumple tarea homeostática, por lo que también se da inhibición de la agregación de dichas células de protección. $^{1}$

\section{Rol general de las prostaglandinas protectoras}

Todos los analgésicos inhibidores de la COX-1 dañan la mucosa gástrica al privarla del efecto citoprotector de prostaglandinas que son las que actúan como generador del moco gástrico y esto es una de las principales razones a considerar, ya que la mayoría de los AINES actúan en la COX-1, también tienen protección, renal, ovario útero (función de constrictor), dolor, inflamación hemostasia, temperatura corporal al actuar al nivel del hipotálamo, por lo que al dar protección a dichas zonas se debe tener consideración al paciente con patologías en donde la COX intervenga, ya que se pueden presentar efectos adversos (Tabla 4). $1,2,9$

Entre los grupos de los antiinflamatorios se pueden encontrar los no narcóticos y los narcóticos derivados del opio, entre los no narcóticos se encuentran los antiinflamatorios no esteroideos, los cuales son los derivados del ácido propiónico (Tabla 5), los oxicanos (Tabla 6), los inhibidores selectivos de la ciclooxigenasa tipo 2 (COXIB) (Tabla 7), los salicilatos (Tabla 8) y entre los que no fungen su acción como AINES, sino como un antiinflamatorio narcótico (Tabla 9) se encuentran los derivados del opio, el efecto de éste no es inhibidor de las prostaglandinas, más bien actúa en la zona encefálica al bloquear la recepción del dolor, esto quiere decir que el dolor está presente, pero su acción deriva en que el paciente omite su presencia al no registrarse en el cerebro, por lo que puede causar adicción. ${ }^{1,2,10}$

A finales del año 2019 hizo su aparición un nuevo coronavirus (SARS-CoV-2), el cual tiene entre sus

Tabla 4: Funciones protectoras de la COX y reacciones adversas en su inhibición.

\begin{tabular}{|c|c|c|c|}
\hline Patología & Acción & Reacciones adversas & Grupo de riesgo \\
\hline Gastrointestinales & $\begin{array}{l}\text { Antiagregante de moco } \\
\text { intestinal protector de la } \\
\text { pared gastrointestinal }\end{array}$ & $\begin{array}{l}\text { Ulceraciones, perforaciones } \\
\text { por sangrado, esofagitis }\end{array}$ & $\begin{array}{l}\text { Intolerancia a AINES, mayores } \\
\text { de } 65 \text { años, úlcera péptica } \\
\text { esofagitis, pancreatitis }\end{array}$ \\
\hline Renal & $\begin{array}{c}\text { Alteración de filtración } \\
\text { glomerular y excreción } \\
\text { de agua y sal }\end{array}$ & $\begin{array}{l}\text { Insuficiencia renal, necrosis } \\
\text { papilar, síndrome nefrótico, } \\
\text { nefritis intersticial, fallo renal }\end{array}$ & $\begin{array}{l}\text { Insuficiencia cardiaca congestiva, } \\
\text { cirrosis, insuficiencia renal, } \\
\text { mayores de } 65 \text { años }\end{array}$ \\
\hline Cardiovascular & $\begin{array}{c}\text { Alteración a la agregación } \\
\text { de tromboxano A2 }\end{array}$ & $\begin{array}{l}\text { Hipertensión arterial, infartos } \\
\text { al miocardio, accidentes } \\
\text { vasculares encefálicos }\end{array}$ & $\begin{array}{l}\text { Pacientes que usan betabloqueadores, } \\
\text { mayores de } 65 \text { años }\end{array}$ \\
\hline Hematológicas & $\begin{array}{l}\text { Alteración a la síntesis } \\
\text { de tromboxano A2 }\end{array}$ & $\begin{array}{l}\text { Hemorragias por intervención } \\
\text { antiagregante plaquetario, } \\
\text { neutropenias, citopenias }\end{array}$ & $\begin{array}{l}\text { Pacientes con indometacina, } \\
\text { fenilbutazona }\end{array}$ \\
\hline Respiratorio & Contracción de vías aéreas & Asma, rinitis, anafilaxia & $\begin{array}{l}\text { Pacientes asmáticos y con } \\
\text { dificultades respiratorias }\end{array}$ \\
\hline Dermatológicas & $\begin{array}{c}\text { Alteración a la síntesis } \\
\text { de tromboxano A2 }\end{array}$ & $\begin{array}{l}\text { Eritema multiforme, } \\
\text { angioedemas, urticaria }\end{array}$ & Pacientes con derivados de oxicanes \\
\hline
\end{tabular}


Tabla 5: Antiinflamatorios no esteroideos (AINES) derivados del ácido propiónico.

\begin{tabular}{|c|c|c|c|}
\hline Medicamento & $\begin{array}{l}\text { Inhibidores } \\
\text { COX }\end{array}$ & Funciones & Contraindicaciones \\
\hline Diclofenaco & $1-2-2$ & $\begin{array}{c}\text { Analgésico } \\
\text { Antirreumático } \\
\text { Dolores osteomusculares }\end{array}$ & $\begin{array}{l}\text { No juntar con otros AINES, } \\
\text { puede causar intoxicación }\end{array}$ \\
\hline Metamizol & $2-2$ & $\begin{array}{l}\text { Analgésico } \\
\text { Antipirético }\end{array}$ & Depresión medular \\
\hline $\begin{array}{l}\text { Paracetamol (acetaminofén) } \\
\text { (No considerado AINES, por lo que es el } \\
\text { fármaco de primera elección en alérgicos) }\end{array}$ & $1-2-2$ & $\begin{array}{l}\text { Analgésico } \\
\text { Antipirético }\end{array}$ & Hepatotóxico \\
\hline Ketorolaco & $1-2-2$ & Analgésico & $\begin{array}{l}\text { Antiagregante plaquetario } \\
\text { Nefrotóxico, retención de líquidos } \\
\text { recetado por más de } 3 \text { días }\end{array}$ \\
\hline Naproxeno & $1-2-2$ & $\begin{array}{c}\text { Analgésico } \\
\text { Antiinflamatorios } \\
\text { Antirreumático } \\
\text { Antipirético }\end{array}$ & Irritación gástrica \\
\hline Ibuprofeno & $1-2-2$ & $\begin{array}{c}\text { Analgésico } \\
\text { Antiinflamatorios } \\
\text { Antirreumático } \\
\text { Antipirético }\end{array}$ & Hipertensos \\
\hline Nimesulida & $1-2-2$ & $\begin{array}{l}\text { Antiinflamatorio } \\
\text { Desinflamatorio }\end{array}$ & $\begin{array}{l}\text { Disminuye capacidad fagocítica de los } \\
\text { macrófagos, por lo que deja vulnerable } \\
\text { al organismo ante invasión bacteriana }\end{array}$ \\
\hline
\end{tabular}

principales características fiebre y dolor articular, por lo que el uso de analgésicos simples y antiinflamatorios son los fármacos más consumidos, al menos $13 \%$ de la población consume fármacos de la familia derivada del opio y continúan con la ingesta de dichos fármacos en la recuperación post-COVID para calmar el periodo de dolor general. Cabe destacar que la disnea es una de las principales características del SARS-CoV-2, estudios demostraron que entre 20 y $60 \%$ de la población que está en recuperación por COVID-19 presentaron secuelas de prevalencia y se prevé que las complicaciones respiratorias pudieran ser una secuela importante, ante ello hay que destacar el uso de AINES en la consulta odontológica por pacientes que están experimentando el periodo post-COVID, ya que algunos de los fármacos pueden ser causantes de efectos adversos en contracciones de las vías aéreas y con ello diseminar la disnea. Por este motivo, hay que conocer las funciones de cada uno de los medicamentos y dónde actúan. ${ }^{11,12}$

\section{Medicamentos derivados del ácido propiónico}

Son los antiinflamatorios de primera elección para el control del dolor y la inflamación, ya que es de los que tienen mejor acción y son más completos. En un estudio realizado se pudo recaudar la información donde se menciona que el AINE más prescrito es el naproxeno $(32.7 \%)$, seguidamente del ibuprofeno (18.6\%), diclofenaco $(10.6 \%)$ y nimesulida $(7.1 \%) .{ }^{13}$

En pacientes con enfermedades gastrointestinales donde la prescripción de fármacos inhibidores de la COX1 puede ser causante de irritabilidad gástrica, los antiinflamatorios conocidos como COXIB son una vía alterna para ello, ya que actúan inhibiendo la ciclooxigenasa 2, aunque con el paso de los años no ha demostrado ser mejor analgésico que los derivados del ácido propiónico, como el ibuprofeno, naproxeno y ketoprofeno, por lo que su elección como una opción principal no siempre será la mejor, además de que es propenso a causar trombosis vascular. ${ }^{1,2,14}$ 


\section{Medicamentos derivados de opiáceos (narcóticos)}

Estos fármacos conocidos como narcóticos son derivados del opio, por lo que su acción es en el sistema nervioso central; sin embargo, se conoce también que cumple con un alto índice de contraindicaciones, las cuales deben considerarse al momento de medicar, la sedación por dolor es muy común con estos fármacos, ya que el dolor está presente en el paciente, no obstante, el bloqueo de los estímulos del dolor hacen que no se registre en el cerebro, por lo que el individuo siente como una

\begin{tabular}{|c|c|c|}
\hline Medicamento & Inhibidores & Función \\
\hline $\begin{array}{l}\text { Dexketoprofeno } \\
\text { (gel) }\end{array}$ & $2-2$ & $\begin{array}{c}\text { Analgésico } \\
\text { Antirreumáticos } \\
\text { Dolores musculares } \\
\text { Antiartrítico }\end{array}$ \\
\hline Meloxicam & $2-2$ & $\begin{array}{c}\text { Analgésico } \\
\text { Antirreumáticos } \\
\text { Dolores musculares } \\
\text { Antiartrítico }\end{array}$ \\
\hline Piroxicam & $2-2$ & $\begin{array}{c}\text { Analgésico } \\
\text { Antirreumáticos } \\
\text { Dolores musculares } \\
\text { Antiartrítico }\end{array}$ \\
\hline
\end{tabular}

analgesia, aunque en realidad la sensación es porque se encuentra en estado de sedación o «drogado» como se conoce, además de que el uso de éstos no tienen función antiinflamatoria ni antirreumática, por lo que el uso de AINES en la práctica odontológica parece ser la de mayor elección y ha demostrado buenos resultados. , $15-17^{\text {Cabe }}$ destacar que $0.9 \%$ de los médicos en atención odontológica usa analgésicos de tipo opioides y $99.1 \%$ refirió no utilizarlos. ${ }^{13}$

Por otra parte, es importante mencionar la diferencia de los antiinflamatorios y desinflamatorios, esto radica en que los AINES son más usados como antiinflamatorio para evitar una posible inflamación, muchas veces postextracción, aunque debemos recordar que el periodo inflamatorio es una respuesta protectora del sistema inmune, así que el hecho de que el paciente presente dicha respuesta es bien vista por el profesional de la salud, ya que da a entender que su sistema está reaccionando de buena manera, un AINE bloquea la síntesis de las prostaglandinas para prevenir una inflamación, por ende su acción no es desinflamatoria, ya que después de una agresión ya se habrá presentado su acción inflamatoria, es decir, que el ácido araquidónico ya se habrá transformado en prostaglandinas, ante una agresión biológica viene la liberación de los mediadores de la inflamación, como lo son la histamina y serotonina y éstas empiezan su acción al haber presencia de prostaglandinas, que es precisamente lo que un medicamento AINE busca bloquear y prevenir mediante la oxidación del ácido araquidónico.

\begin{tabular}{|c|c|c|c|}
\hline Medicamento & Inhibidor COX & Función & Contraindicaciones \\
\hline Celecoxib & $2-2$ & $\begin{array}{c}\text { Analgésico } \\
\text { Antirreumático }\end{array}$ & $\begin{array}{l}\text { Poca actividad analgésica } \\
\text { Trombosis vascular }\end{array}$ \\
\hline Rofecoxib & $2-2$ & $\begin{array}{c}\text { Analgésico } \\
\text { Antirreumático }\end{array}$ & $\begin{array}{l}\text { Poca actividad analgésica } \\
\text { Trombosis vascular }\end{array}$ \\
\hline Etoricoxib & $2-2$ & $\begin{array}{c}\text { Analgésico } \\
\text { Antirreumático }\end{array}$ & $\begin{array}{l}\text { Poca actividad analgésica } \\
\text { Trombosis vascular }\end{array}$ \\
\hline Parecoxib & $2-2$ & $\begin{array}{c}\text { Analgésico } \\
\text { Antirreumático }\end{array}$ & $\begin{array}{l}\text { Poca actividad analgésica } \\
\text { Trombosis vascular }\end{array}$ \\
\hline Valdecoxib & $2-2$ & $\begin{array}{c}\text { Analgésico } \\
\text { Antirreumático }\end{array}$ & $\begin{array}{l}\text { Poca actividad analgésica } \\
\text { Trombosis vascular }\end{array}$ \\
\hline
\end{tabular}

COXIB = inhibidores selectivos de la ciclooxigenasa tipo 2. 


\section{Tabla 8: Salicilatos.}

\begin{tabular}{cccc} 
Medicamento & Inhibidor COX & Función & Contraindicaciones \\
\hline Ácido acetilsalicílico (aspirina) & 1 & Antipirético & Antiagregante plaquetario \\
& & Antirreumático & Irtación gástrica \\
& & & $\begin{array}{c}\text { Asma inducida } \\
\text { ínenos }\end{array}$ \\
Clonixinato de lisina (dorixina) & $1-2-2$ & Analgésico & Dosis de 1 a 2 mg diarios retiene ácido úrico \\
& & Antiagregante plaquetario \\
& & Irritación gástrica \\
\hline
\end{tabular}

Tabla 9: Medicamentos opioides narcóticos.

\begin{tabular}{|c|c|c|c|}
\hline Medicamento & Descripción & Función & Efectos adversos \\
\hline Tramadol & $\begin{array}{c}\text { Receptores morfínicos } \\
\text { del cerebro }\end{array}$ & $\begin{array}{l}\text { Analgesia potente (no quita el dolor, } \\
\text { sólo hace que no se registre) }\end{array}$ & $\begin{array}{c}\text { Depresión respiratoria } \\
\text { Adicción } \\
\text { Sensación de bienestar } \\
\text { Cefaleas } \\
\text { Vómito } \\
\text { Convulsiones }\end{array}$ \\
\hline Dextropropoxifeno & $\begin{array}{c}\text { Receptores morfínicos } \\
\text { del cerebro }\end{array}$ & $\begin{array}{l}\text { Analgesia potente (no quita el dolor, } \\
\text { sólo hace que no se registre) }\end{array}$ & $\begin{array}{c}\text { Depresión respiratoria } \\
\text { Adicción } \\
\text { Sensación de bienestar } \\
\text { Cefaleas } \\
\text { Vómito } \\
\text { Convulsiones }\end{array}$ \\
\hline Meperidina & $\begin{array}{c}\text { Receptores morfínicos } \\
\text { del cerebro }\end{array}$ & $\begin{array}{l}\text { Analgesia potente (no quita el dolor, } \\
\text { sólo hace que no se registre) }\end{array}$ & $\begin{array}{c}\text { Depresión respiratoria } \\
\text { Adicción } \\
\text { Sensación de bienestar } \\
\text { Cefaleas } \\
\text { Vómito } \\
\text { Convulsiones }\end{array}$ \\
\hline Propoxifeno & $\begin{array}{c}\text { Receptores morfínicos } \\
\text { del cerebro }\end{array}$ & $\begin{array}{l}\text { Analgesia potente (no quita el dolor, } \\
\text { sólo hace que no se registre) }\end{array}$ & $\begin{array}{c}\text { Depresión respiratoria } \\
\text { Adicción } \\
\text { Sensación de bienestar } \\
\text { Cefaleas } \\
\text { Vómito } \\
\text { Convulsiones }\end{array}$ \\
\hline
\end{tabular}

\section{Desinflamatorios}

Cuando ya hay presencia de inflamación por razones físicas como se ha mencionado anteriormente (pueden ser traumáticas o por cirugía oral), como control de la misma o uso desinflamatorio, las enzimas proteolíticas y fibrolíticas, que no son AINES, pueden ser útiles a la hora de tratar al paciente en una urgencia médica odontológica, ya que sus indicaciones son como tratamiento en la inflamación aguda, es decir, cuando ésta ya está presente. ${ }^{18-21}$ 
Al haber agresión en una zona local se crea inflamación, por lo que el sistema rodea el exudado inflamatorio con una membrana piógena compuesto por una red de fibrina, esta membrana está formada por hemidesmosoma y forman un desmosoma, en el cual la sustancia esencial de unión es el ácido hialurónico, las enzimas proteolíticas y fibrinolíticas se unen y rompen el ácido hialurónico, por lo que la fibrina ya no hace su presencia de esa manera y el exudado puede dispersarse, lo que disminuye el edema inflamatorio; no obstante, esto también puede traer como consecuencia la diseminación del exudado a otra parte de la fisiología humana si la causa de la inflamación es infeccioso, por ello en el examen clínico es importante descartar que la inflamación no es causada por una infección para poder hacer uso de estos fármacos. Entre las causas inflamatorias donde se puede hacer uso de estos fármacos estarían los agentes físicos, como puede ser alguna agresión por golpe o accidente, químicos en la exposición de algún agente irritante que cause dicha inflamación o inflamación postextracción por manipulación constante.

Se ha reportado el uso de estas enzimas proteolíticas y fibrinolíticas con lesiones en deportistas que sufren alguna agresión, al no ser causada por infección y al no haber presencia de exudado supurativo, éstas son alternativas para tratar la inflamación: en el caso particular de la estreptoquinasa y estreptodornasa «varidasa» actúan a nivel de la fibrina mencionada con anterioridad, ya que a nivel del plasminógeno activa la plasmina que bloquea la función de la fibrina, por lo que habría presencia de edema, recordemos que la fibrina es la causante de la unión de las células de inflamación; las demás opciones para el tratamiento de la inflamación se muestran en la Tabla 10". ${ }^{18-21}$

\section{Dexametasona como auxiliar desinflamatorio}

Los glucocorticoides son fármacos antiinflamatorios y antialérgicos derivados de la cortisona y como consecuencia son usados en presencia de inflamación, se puede mencionar como un desinflamatorio cuando ya hay presencia de edema, ya que en diferentes estudios ha demostrado ser un excelente fármaco de elección para la reducción de procesos inflamatorios y dolor, garantizando así la buena recuperación. Cabe señalar que es uno de los fármacos del que se ha estado haciendo uso en el campo de la odontología, esto como respuesta ante la presencia de una inflamación por trauma, o bien por efectos postextracción; la dosis recomendada

Tabla 10: Antiinflamatorios derivados de enzimas proteolíticas y fibrinolíticas.

\begin{tabular}{|c|c|c|c|}
\hline Medicamento & Descripción & Función & Contraindicaciones \\
\hline \multirow{2}{*}{$\begin{array}{l}\text { Estreptoquinasa } \\
\text { (Varidasa) }\end{array}$} & Obtenido del & Activa el plasminógeno y & \multirow{4}{*}{$\begin{array}{l}\text { Hipersensibilidad a la estreptoquinasa, } \\
\text { hipertensión grave no controlada, niveles bajos } \\
\text { de fibrinógeno, trombocitopenia, tratamiento con } \\
\text { antiagregantes plaquetarios o anticoagulantes } \\
\text { podría aumentar el riesgo de hemorragia } \\
\text { Hipersensibilidad a la estreptoquinasa, } \\
\text { hipertensión grave no controlada, niveles bajos } \\
\text { de fibrinógeno, trombocitopenia, tratamiento con } \\
\text { antiagregantes plaquetarios o anticoagulantes } \\
\text { podría aumentar el riesgo de hemorragia }\end{array}$} \\
\hline & $\begin{array}{l}\text { Streptococcus } \\
\text { beta hemolítico }\end{array}$ & $\begin{array}{l}\text { lo convierte en plasmina, } \\
\text { lo que degrada a la fibrina } \\
\text { y permite la eliminación } \\
\text { por vía linfática }\end{array}$ & \\
\hline $\begin{array}{l}\text { Estreptodornasa } \\
\text { (Varidasa) }\end{array}$ & $\begin{array}{c}\text { Propiedad } \\
\text { antiademosa }\end{array}$ & $\begin{array}{l}\text { Degradación enzimática } \\
\text { de exudados supurativos }\end{array}$ & \\
\hline & & & \\
\hline Serratiopeptidasa & $\begin{array}{l}\text { Antiinflamatorio } \\
\text { y fibrinolítico } \\
\text { (mucolítico) }\end{array}$ & $\begin{array}{l}\text { Eliminación de secreción } \\
\text { mucopurulenta, reducción } \\
\text { de exudado purulento }\end{array}$ & $\begin{array}{l}\text { Hipersensibilidad al agente, } \\
\text { hipoprotrombinemia, pancreatitis aguda, } \\
\text { cuidado en pacientes con anticoagulantes }\end{array}$ \\
\hline $\begin{array}{c}\text { Tripsina y } \\
\text { quimotripsina }\end{array}$ & Antiinflamatorio & $\begin{array}{l}\text { Destrucción de barrera de } \\
\text { fibrina que rodea el edema }\end{array}$ & Posibles reacciones anafilácticas \\
\hline Bromelinas & $\begin{array}{l}\text { Enzima proteolítica, } \\
\text { antiinflamatorio y } \\
\text { antiedematoso }\end{array}$ & $\begin{array}{l}\text { Reducción de migración } \\
\text { de neutrófilos a sitios } \\
\text { inflamatorios }\end{array}$ & $\begin{array}{l}\text { Hipersensibilidad al agente, cuidado con } \\
\text { pacientes con terapia anticoagulante. Irritabilidad } \\
\text { en piel y ojos, alergias respiratorias }\end{array}$ \\
\hline
\end{tabular}


Tabla 11: Dexametasona.

\begin{tabular}{llll} 
Fármaco & Descripción & Función & Contraindicaciones \\
\hline Dexametasona & $\begin{array}{l}\text { Glucocorticoide derivado } \\
\text { de la hidrocortisona }\end{array}$ & $\begin{array}{l}\text { Antiinflamatorio, inmunosupresor } \\
\text { actuando en la inhibición del ácido } \\
\text { araquidónico }\end{array}$ & $\begin{array}{l}\text { Hiperglucemia, hipertensión, osteo- } \\
\text { porosis, irregularidades menstruales, } \\
\text { amenorrea }\end{array}$
\end{tabular}

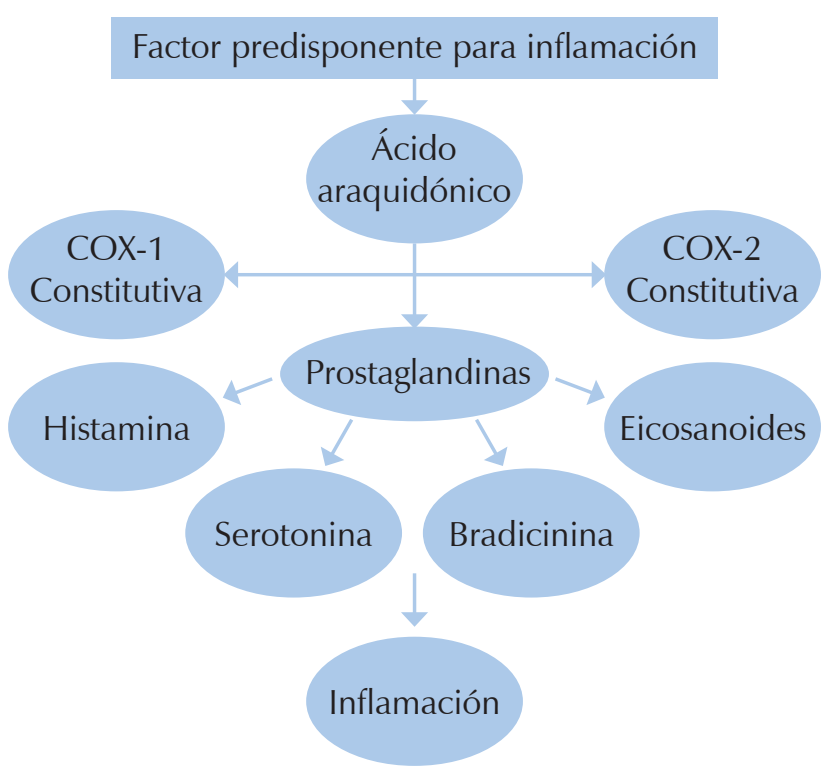

Figura 1: Fisiopatología de la inflamación.

en uso odontológico es de una inyección de $8 \mathrm{mg}$ por $2 \mathrm{~mL}$, es preciso mencionar que a pesar de ser un gran antiinflamatorio es también causante de muchos efectos adversos con gran potencial elevado como se menciona en la Tabla 11. Es por ello que su bajo uso es reflejado en un estudio realizado en Colombia, donde los resultados indican que $15.8 \%$ no usa dexametasona en ningún momento, $68.4 \%$ de los cirujanos orales y maxilofaciales lo usa con baja frecuencia, $13.2 \%$ lo usa con mediana frecuencia y $2.6 \%$ con frecuencia alta; sin embargo, es importante esta información para tener en cuenta su uso en determinado momento de la consulta odontológica por urgencia. ${ }^{22}$

En México, un estudio realizado con 113 cirujanos dentistas de práctica general y estudiantes de la carrera en cirujano dentista demuestra que $7.1 \%$ prescribe glucocorticoides, mientras que el otro $92.9 \%$ no los recomienda. ${ }^{13}$

\section{CONCLUSIÓN}

Después de haber estudiado la fisiopatología de la inflamación y el dolor, sabemos dónde es el sitio de acción de los antiinflamatorios no esteroideos y de los que no entran en la clasificación, pero que son fármacos que rodean el ámbito odontológico para el control del dolor y la inflamación. Ahora podemos identificar cómo hacer uso de cada uno de ellos en momentos en los que el paciente se presente en la consulta; hay una gran variedad de elecciones donde muchas veces éstas no son del conocimiento del profesional de la salud bucal. Por otra parte, es importante realizar una buena anamnesis para conocer el origen del malestar inflamatorio, ante ello hacemos uso de un fármaco que sabemos que llegará al sitio de acción que queremos, al igual que conocemos las contraindicaciones de cada uno de ellos.

Podemos mencionar que ante el estudio de este trabajo y de los muchos otros revisados, se llega a la conclusión de que los fármacos de primera elección son los derivados del ácido propiónico como lo son el ibuprofeno, naproxeno, con una mayor acción analgésica y antiinflamatoria y menor efecto adverso; ante la presencia de alergia, el uso del acetaminofén (paracetamol) se recomienda como el fármaco de primera elección, siempre tomando en cuenta que si la causa de dicha inflamación es infecciosa, el uso de antibióticos es de vital importancia, cabe mencionar que los AINES son los indicados en esos casos.

Para finalizar, ya sabemos un poco de la variación de medicamentos que tenemos en la carpeta de fármacos para elegir, esto nos ayudará a dar una mejor atención al paciente ante las urgencias odontológicas y nos hará crecer en el campo de conocimientos farmacológicos, que muchas veces en el ejercicio odontológico se queda limitado ante sólo algunos de los medicamentos que nos mencionan en la licenciatura. La constante actualización nos dará mejores resultados a la atención de nuestros pacientes, recordando siempre que son la razón de nuestra profesión, por lo que estamos obligados a brindarles 
atención de calidad y para ello es de vital importancia conocer las amplias opciones que tenemos.

\section{Primum non nocere. Hipócrates.}

\section{REFERENCIAS}

1. Gómez De Salazar JR, Santos Soler G, Martin Domenéch R, Cortes Berdú R, Álvarez Cienfuegos A. Capítulo 26: Antiinflamatorios no esteroideos. Sección Reumatología, Hospital Marina Baixa, Villajosa Alicante. Hospital de Xativa, Valencia, Hospital de Orihuela, Alicante.

2. Pérez Ruiz AA, López Mantecón AM, Grau León I. Antiinflamatorios no esteroideos (AINES): Consideraciones para su uso estomatológico. Rev Cubana Estomatol. 2002; 39 (2): 119-138.

3. Galán Peñaloza JR. Uso de los analgésicos opioides en el campo odontológico [Tesis]. Guayaquil: Universidad de Guayaquil; 2015.

4. Coley Silva LF, Ahumada Navarro WE. Modelo de uso de la planta medicinal Bursera simaruba y su actividad antiinflamatoria. Barranquilla: Universidad Libre Seccional Barranquilla; 2019.

5. González-Costa M, Padrón González AA. La inflamación desde una perspectiva inmunológica: desafío a la Medicina en el siglo XXI. Rev Haban Cienc Méd. 2019; 18 (1): 30-44.

6. Pascuzzo C. Inducción a la farmacología autocide. Farmacología Histaminergica. Maravel Morgan.

7. Vega Robledo G. Inflamación. Rev Fac Med UNAM. 2008; 51 (5): 220-222.

8. León Regal M, Alvarado Borges A, de Armas García J, Miranda Alvarado L, Varens Cedeño J, Cuesta del Sol J. Respuesta inflamatoria aguda. Consideraciones bioquímicas y celulares: cifras alarmantes. Rev Finlay. 2015; 5 (1): 47-62.

9. Batlouni M. Antiinflamatorios no esteroides: efectos cardiovasculares, cerebrovasculares y renales. Arq Bras Cardiol. 2010; 94 (4): 538546.

10. Muriel C, Santos J, Sánchez-Montero F. Farmacología de los analgésicos no opiáceos (AINES). Máster del Dolor.

11. González del Castillo J, Rodríguez Machuca MJ, Casasus MA, Sánchez García A. Secuelas de la infección por SARS-CoV-2. Un problema que debe ser afrontado. Rev Méd Chile. 2020; 148 (9): 1373-1374.

12. Micó Segura JA. Coronavirus COVID-19 y dolor crónico: incertidumbres. Rev Soc Esp Dolor. 2020; 27 (2): 72-73.

13. Flores RJM, Ochoa ZMG, Romero PJJ, Barraza SH. Analgésicos en odontología: resultados de una encuesta sobre su uso clínico. Rev ADM. 2014; 71 (4): 171-177.
14. Salido M, Abásolo L, Bañares A. Revisión de los antiinflamatorios inhibidores selectivos de la ciclooxigenasa 2. Inf Ter Sist Nac Salud. 2001; 25 (2): 46-52.

15. Sáenz Campos D, Saborio Montoya MA. Revisión terapéutica de la analgesia en odontología. Revista Costarricense de Ciencias Médicas. 1990; 11 (1): 75-82.

16. Castillo F. Dextropropoxifeno: propuesta de suspensión en Europa. Actualidad Científica Farmacovigilancia. Agencia Española del Medicamento.

17. Romero-Ruiz MM, Herrero-Climent M, Torres-Lagares D, Gutiérrez-Pérez JL. Protocolo de control del dolor y la inflamación postquirúrgica: Una aproximación racional. RCOE. 2006; 11 (2): 205-215.

18. Industria Farmacéutica Cantabria. Agencia Española de Medicamentos y Protocolos Sanitarios. 2007.

19. López Quiles J. La tripsina en el tratamiento de lesiones deportivas agudas. Rev Med Hondur. 1968.

20. Zera Moraya JW. Efecto de la bromelina en la concentración sérica y ósea de clindamicina [Tesis]. Lima, Perú: Universidad Nacional Mayor de San Marcos; 2012.

21. Tiwari M. The role of serratiopeptidase in the resolution of inflammation. Asian J Pharm Sci. 2017; 12 (3): 209-215.

22. Amorocho Barrios JC, Pedraza Daza GA, Remolina Martínez MA. Uso de dexametasona en odontología. Colombia: Universidad Santo Tomas Bucaramanga; 2019.

Conflicto de intereses: Sin conflicto de intereses ni fines de lucro más que el aprendizaje continuo y ético.

Aspectos éticos: En busca de la enseñanza y actualización continua, honestidad y lealtad a la información obtenida en otros medios bibliográficos con el fin de presentar y conocer más sobre el tema farmacológico en el medio odontológico.

Financiamiento: Sin fines de lucro, el estudio realizado por medio de artículos bibliográficos obtenidos en páginas de Internet con artículos científicos publicados y certificados.

Correspondencia:

Alberth Francisco Keb Canul

E-mail: alberthkebc1@gmail.com 